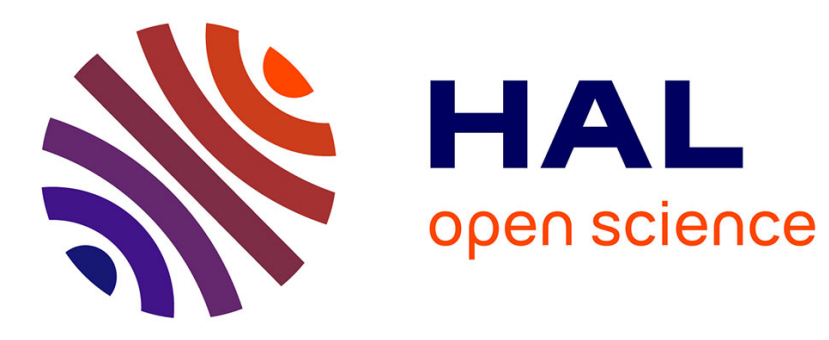

\title{
Influence of the grade on the variability of the mechanical properties of polypropylene waste
}

Hamdi Jmal, Nadia Bahlouli, Christiane Wagner-Kocher, Dimitri Leray, Frédéric Ruch, Jean-Nicolas Munsch, Michel Nardin

\section{- To cite this version:}

Hamdi Jmal, Nadia Bahlouli, Christiane Wagner-Kocher, Dimitri Leray, Frédéric Ruch, et al.. Influence of the grade on the variability of the mechanical properties of polypropylene waste. Waste Management, 2018, 75, pp.160-173. 10.1016/j.wasman.2018.02.006 . hal-01712286

\section{HAL Id: hal-01712286 \\ https://hal.science/hal-01712286}

Submitted on 19 Feb 2018

HAL is a multi-disciplinary open access archive for the deposit and dissemination of scientific research documents, whether they are published or not. The documents may come from teaching and research institutions in France or abroad, or from public or private research centers.
L'archive ouverte pluridisciplinaire HAL, est destinée au dépôt et à la diffusion de documents scientifiques de niveau recherche, publiés ou non, émanant des établissements d'enseignement et de recherche français ou étrangers, des laboratoires publics ou privés. 


\title{
Influence of the grade on the variability of the mechanical properties of polypropylene waste
}

\author{
Hamdi Jmal ${ }^{\mathrm{a}}$, Nadia Bahlouli ${ }^{\mathrm{a}, *}$, Christiane Wagner-Kocher ${ }^{\mathrm{b}, \mathrm{c}}$, Dimitri Leray ${ }^{\mathrm{d}}$, Frédéric Ruch ${ }^{\mathrm{d}}$, \\ Jean-Nicolas Munsch ${ }^{\mathrm{e}}$, Michel Nardin ${ }^{\mathrm{e}}$ \\ a ICube, Université de Strasbourg, CNRS, 2-4 rue Boussingault, 67000 Strasbourg, France \\ ${ }^{\mathrm{b}}$ LPMT - ENSISA, Université de Haute Alsace, Mulhouse, 11 rue Alfred Werner, 68093 Mulhouse, France \\ ${ }^{\mathrm{C}}$ LMGC, Univ. Montpellier, CNRS, Montpellier, France \\ ${ }^{\mathrm{d}}$ Cetim-Cermat, 21 Rue de Chemnitz, 68200 Mulhouse, France \\ e Institut de Science des Matériaux de Mulhouse (IS2M), UMR 7361, 15 Jean Starcky, 68057 Mulhouse, France
}

Keywords:

Recycled polypropylene

Grade, strain rate effect

Additive effect

Mechanical property

\begin{abstract}
A B S T R A C T
The prior properties of recycled polypropylene depend on the origin of waste deposits and its chemical constituents. To obtain specific properties with a predefine melt flow index of polypropylene, the suppliers of polymer introduce additives and fillers. However, the addition of additives and/or fillers can modify strongly the mechanical behaviour of recycled polypropylene. To understand the impact of the additives and fillers on the quasi-static mechanical behaviour, we consider, in this study, three different recycled polypropylenes with three different melt flow index obtained from different waste deposits. The chemical constituents of the additives and filler contents of the recycled polypropylenes are determined through thermo-physico-chemical analysis. Tensile and bending tests performed at different strain rates allow identifying the mechanical properties such as the elastic modulus, the yield stress, the maximum stress, and the failure mechanisms. The results obtained are compared with non-recycled polypropylene and with few researches to explain the combined effect of additives. Finally, a post-mortem analysis of the samples was carried out to make the link between the obtained mechanical properties and microstructure.
\end{abstract}

\section{Introduction}

Polypropylene (Rust et al., 2006) and its compounds (Ai Wah et al., 2000; Brandrup, 1996) are characterized by an interesting spectrum of mechanical properties such as: the low density, the good stiffness, the acceptable elastic limit and the high resistance to ageing. They are widely used to replace numerous metals in automotive parts in order to achieve weight and coast saving (Pessey et al., 2008). Generally, the polypropylene is frequently blended with elastomers or mineral fillers to obtain specific properties. For manufacturing car bumpers, it has been shown that Ethylene Propylene Rubber (EPR) and Ethylene Propylene Diene (EPDM) can be added to increase the inherent low toughness of PP at low temperature (Bahlouli et al., 2006; Pessey et al., 2010;

\footnotetext{
* Corresponding author.

E-mail addresses: jmal@unistra.fr (H. Jmal), nadia.bahlouli@unistra.fr (N. Bahlouli), christiane.wagner-kocher@umontpellier.fr (C. Wagner-Kocher), dle@ Cetim-Cermat.fr (D. Leray), fr@cetim-cermat.fr (F. Ruch), jean-nicolas.munsch@uha. fr (J.-N. Munsch), michel.nardin@uha.fr (M. Nardin).
}

Rogueda-Berriet et al., 2011). Several researches have been focused in the influence of these additives on the microstructure and the mechanical behaviour of polymers. The effect of additives and fillers is very complex. It depends on many factors: the microstructure of polymer, the additive quantities, the types of filler, the possible interactions between additives, their dispersion in the polymers, the ratio aspect (Guerrica-Echevarría et al., 1996), the additive size (Guerrica-Echevarría et al., 1996; Rogueda-Berriet et al., 2011; Strapasson et al., 2005), the processing conditions such as temperature (Guerrica-Echevarría et al., 1996; Strapasson et al., 2005) and flow rate (Guerrica-Echevarría et al., 1996), etc. The addition of Calcium Carbonate $\left(\mathrm{CaCO}_{3}\right)$ and talc are used to increase the stiffness and the dimensional stability of the polymers (Eiras and Pessan, 2009; Ingram et al., 2008; Zuiderduin et al., 2003). Thus, comparing to neat PP, the elastic modulus and yield stress of $\mathrm{PP} / \mathrm{CaCO}_{3}$ nanocomposites increase significantly with the addition of rigid particle contents. Comparing to small amount of $\mathrm{CaCO}_{3}$ nanoparticles, the experimental results of Eiras and Pessan (2009) show that both elastic modulus and yield stress remain constants with the increase of particle contents. Contrary, 
Zuiderduim et al. (2003) show that the elastic modulus of PP/ $\mathrm{CaCO}_{3}$ is increasing with the particle contents. This difference is due to the effect of dispersion of $\mathrm{CaCO}_{3}$ particles in matrix polymer which is due to the process. The mechanical properties of $\mathrm{PP} / \mathrm{CaCO}_{3}$ depend not only on the amount and particle dispersion but also on the particle sizes and particle surface treatments. Generally, $\mathrm{CaCO}_{3}$ must verify requirements to act as toughness agent. Among these requirements, we cite the aspect ratio close to unity, the smaller size (inferior to $5 \mu \mathrm{m}$ ) and the homogeneous dispersion of particle in matrix polymer. These requirements allow insuring a particle debonding prior to yield strain of the matrix polymer in order to change the stress state of the matrix polymer and initiate the shear yielding. Thus, the material becomes able to absorb large quantities of energy upon fracture. The addition of carbonate particles can decrease the brittle-to-ductile transition temperature of polypropylene near to room temperature indicating that the plastic resistance of matrix is reduced as result of debonding and stress softening (Eiras and Pessan, 2009; Zuiderduin et al., 2003).

The raising use of PP and its compounds causes an increase of its wastes. Despite the great selection efforts of suppliers (Serranti et al., 2015; Tang and Brouwers, 2017; Wang et al., 2015), the materials provided from plastic waste are usually a mixture of several polymers such as polypropylene (PP), poly (ethylene-terephthalate) and polyethylene (PE). The incompatibility between PE and PP has already been reported in various investigations (Bertin and Robin, 2002; Teh et al., 1994). The immiscibility between PP and PE phases induces a decrease in mechanical properties such as the impact strength, strain at break and ductile to brittle transition. To overcome the effects of the immiscibility, compatilizing agents, like ethylene-propylenediene monomer copolymer (EPDM) or PE-g (2-methyl-1, 3 butadiene) graft copolymer, are used to enhance the impact strength and elongation at break (Teh et al., 1994). To study the PP/LPDE blends, a different PE mass fraction has been considered (Bertin and Robin, 2002; Kolarik, 1996; Strapasson et al., 2005). The elastic modulus and yield strength decrease linearly with the blend composition. However, the elongation at break presents a minimum for the blend of $50 \%$ weight fraction of PE. R. Strapasson et al. have shown the dependence of mechanical behaviour of PP/PE blends on processing temperature (Strapasson et al., 2005).

The polymers are usually classified according to their Melt Flow Index, called grade (MFI of polymer = grade of polymer). The melt flow index is a measure of the ease of flow of melted plastics and represents a typical index for quality control of thermoplastics. The MFI is inversely related to molecular weight. A practical way to increase the MFI is to add peroxide which acts as a polymer chain scission agent. In this case of neat polypropylene, the increase of MFI (decrease of molecular weight by decreasing the molecular length) induces the increase of the chain's mobility and its ability to fold, allowing the formation of crystalline network and higher degree of crystallinity (Rogueda-Berriet et al., 2011). The polymer chains scission explains the increase of elastic modulus and yield stress, as well as the decrease of strength, elongation at break and fracture toughness with the increase of MFI (grade) (Aurrekoetxea et al., 2001). Therefore, for neat polymer materials, MFI (grade) is an important physical measure which is related indirectly to mechanical properties. The plastics engineer should choose a material with a melt flow index high enough that the molten polymer can be easily formed into the article intended, but low enough that the mechanical strength of the final article will be sufficient for its use.

Recycling of polymers is interesting for economic and environmental reasons. However, the environment aging, the longer exposure to high temperatures, the intensive melt shearing and the presence of moisture during recycling process may give rise to thermal, thermo-oxidative and mechanical degradations. The effects recycling in polypropylene were intensively studied (Aurrekoetxea et al., 2001; Guerrica-Echevarría et al., 1996; Hinsken et al., 1991; Kolarik, 1996). During reprocessing of PP, Hinsken et al. reported oxidation degradation reactions which lead to products containing double bonds and carbonyl groups (Hinsken et al., 1991). To inhibit oxidation and possible changes in the chemical structure of PP, it is important to use antioxidant and stabilizers (Aurrekoetxea et al., 2001; Guerrica-Echevarría et al., 1996; Kolarik, 1996). In this case, the main effect of recycling is the lowering of melt viscosity, which is attributed to melt flow index (MFI) increase and to molecular weight decrease. In the case of isotactic polypropylene, J. Aurrekoetxea et al. showed an increase of elastic modulus and yield stress and a decrease of elongation at break and fracture toughness with the number of recycling steps (Aurrekoetxea et al., 2001). The authors attributed the increase of elastic modulus and yield stress with recycling to the high crystallinity of the recycled PP which hinders rotation of chain segments and thus reduces the flexibility. The decrease of elongation at break and fracture toughness with repeated processing cycles can be explained by the lowering of molecular weight which allows insertion of more chain ends into the structure, resulting in fewer chains completely integrated into the crystal to sustain stress during tensile loading. G. Guerrica et al. studied the effects of repetitive injection moulding cycles at different temperatures and shear rates on the mechanical properties of unfilled and talc-filled polypropylene. In contrast to neat PP, the yield stress of the filled Polypropylene shows a small decrease with reprocessing (Guerrica-Echevarría et al., 1996).

The recycled polypropylenes are classified according to their melt flow index, called grade. Different grades depend on additives and fillers. Generally, it is necessary to consider just one type of additives to understand its effect. Contrary, this study focused on three different grades of recycled polypropylene: grade 3 , grade 10 and grade 54 which contain different amounts and types of additives and fillers to determine their combined effects on the mechanical behaviour, the elastic properties, the strength, the break properties and the failure mechanisms. Tensile and bending tests are conducted in different strain rates to evaluate the effect of strain rate on mechanical behaviour of recycled polypropylene. Finally, the mechanical characteristic (Young modulus, yield stress, strength, etc.) of the recycled polypropylene are compared with a virgin PP.

\section{Experimental procedure}

\subsection{Materials}

To investigate the combined effects of additives, contaminants and grade (MFI) on the mechanical properties of recycled polypropylene, three references, distinguished by their melt flow index (grades), were provided by 'Paprec Plastique' (Table 1, Fig. 1-c). They are obtained from an industrial process which begins with storing the 'polypropylene' waste deposits (containers, bumper, etc.) into three different categories. After adding fillers and peroxide, the recycled PP of grades 3, 10 and 54 are respectively obtained from the first, second and third deposit categories. Thus, some of the chemical components found in these references (Table 1) are added by suppliers and others are contaminants.

In order to determine the effect of recycling, virgin polypropylene of grade 12, designed by PP12(V) has been considered (Table 1, Fig. 1-c). PP12(V) is a homopolymer reference Moplen HP500 that is highly isotactic grade produced by 'Lyondellbasell' (Frankfurt am Main, Germany). The recycled and virgin PP are initially provided in pellet form. Virgin and recycled PP pellets are obtained by extrusion in the same process conditions. The test specimens are then 
Table 1

Physicochemical properties of the recycled and virgin PP.

\begin{tabular}{|c|c|c|c|c|c|}
\hline \multicolumn{2}{|l|}{ Designation } & PP3 (R) & PP10 (R) & PP54 (R) & PP12 (V) \\
\hline \multicolumn{2}{|l|}{ Injection temperature $\left({ }^{\circ} \mathrm{C}\right)$} & 220 & 220 & 220 & 220 \\
\hline \multicolumn{2}{|c|}{ Melt Flow index (MFI/grade) (g/10 min) } & 3 & 10.3 & 54.1 & 12 \\
\hline \multicolumn{2}{|l|}{ Density $\left(\mathrm{g} / \mathrm{cm}^{3}\right)$} & 0.968 & 0.951 & 0.923 & 0.900 \\
\hline \multirow{9}{*}{$\begin{array}{l}\text { Colour } \\
\text { Physicochemical analyses }\end{array}$} & & Grey & Black & White & Transparent \\
\hline & Polymers & $\mathrm{PP} / \mathrm{PE}^{\mathrm{c}}$ & $\mathrm{PP} / \mathrm{PE}^{\mathrm{b}}$ & $\mathrm{PP} / \mathrm{PE}^{\mathrm{a}}$ & $\mathrm{PP}$ \\
\hline & Molecular weight $M_{\omega}(\mathrm{g} /$ mole $)$ & 273,000 & 215,800 & 156,000 & - \\
\hline & Crystallinity degree $\chi_{c}(\%)$ & 38 & 41 & 41 & - \\
\hline & Additive amount (\%) & 8.3 & 4.1 & 2.5 & $\approx 0$ \\
\hline & Additive and contaminant types & $\mathrm{CaCO}_{3} 5 \%$ & Brome $^{a}$ & Modified peroxide $^{c}$ & \\
\hline & & & $\mathrm{CaCO}_{3} 1.8 \%$ & & \\
\hline & & & Carbon particle ${ }^{a}$ & & \\
\hline & & & Modified peroxide ${ }^{b}$ & & \\
\hline
\end{tabular}

\footnotetext{
a Small amount.

b Medium amount.

c Large amount, (R): Recycled PP, (V): Virgin PP.
}

(a)

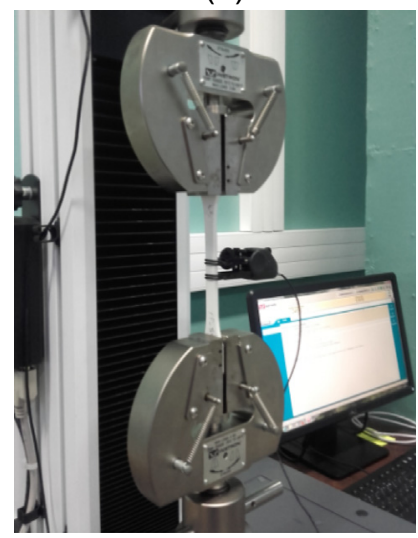

(b)

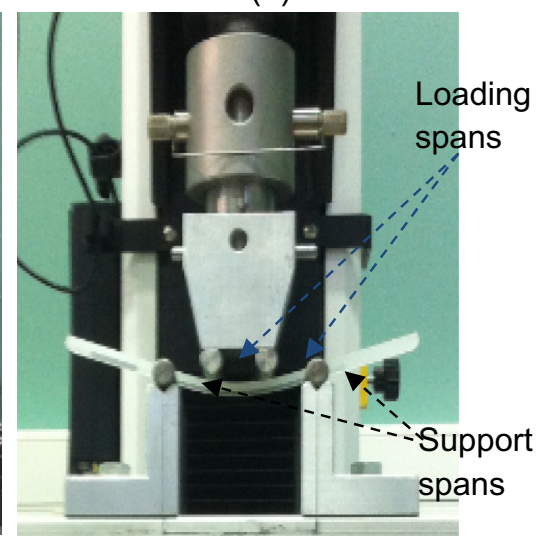

(c)

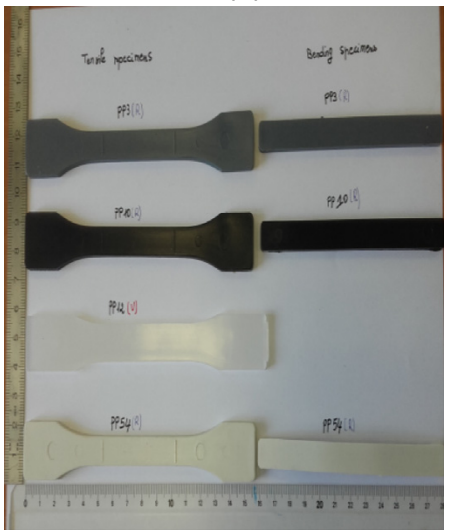

Fig. 1. Test devices and specimens: (a) tensile device, (b) 4-point bending device, (c) tensile and bending specimens.

manufactured by injection in quasi-steady temperatures between $220^{\circ} \mathrm{C}$ and $230^{\circ} \mathrm{C}$. The injection process conditions such as extruder rotation speed, temperatures, humidity are maintained constant for both recycled and virgin PP to avoid the process condition effects.

Physicochemical analysis based on thermogravimetry (TGA), differential scanning calorimetry (DSC) and Fourier transform infrared spectroscopy (FITR) have been performed in order to determine the chemical structure of recycled PP (Table 1). The thermogravimetric analyses were carried out in three steps using a Metter TGA 50. The first step consists in increasing temperature from $25^{\circ} \mathrm{C}$ to $600{ }^{\circ} \mathrm{C}$. In the second step, the temperature is decreased from $600{ }^{\circ} \mathrm{C}$ to $400{ }^{\circ} \mathrm{C}$ and then is maintained at $400{ }^{\circ} \mathrm{C}$ during three minutes. Finally, the third step consists in increasing temperature to $800{ }^{\circ} \mathrm{C}$ and then maintaining this temperature during $30 \mathrm{~min}$. We note that the first and second steps are achieved in nitrogen gas flowing $(200 \mathrm{ml} / \mathrm{min})$. However the third step is carried out in air $(200 \mathrm{ml} / \mathrm{min})$. The temperature rate during all steps of TGA is equal $20^{\circ} \mathrm{C} / \mathrm{min}$. The calorimetric analyses were carried out using a Mettler DSC 30 in nitrogen gas flowing at a rate of $200 \mathrm{ml} / \mathrm{min}$. The DSC method consists firstly in increasing temperature from $-120^{\circ} \mathrm{C}$ to $220^{\circ} \mathrm{C}$ at $10^{\circ} \mathrm{C} / \mathrm{min}$, secondly in decreasing from $220^{\circ} \mathrm{C}$ to $-120^{\circ} \mathrm{C}$ at $20^{\circ} \mathrm{C} / \mathrm{min}$ and finally in increasing from $-120^{\circ} \mathrm{C}$ to $220^{\circ} \mathrm{C}$ at $10^{\circ} \mathrm{C} / \mathrm{min}$.

The physicochemical analyses show the presence of low and medium density polyethylene in the three references of recycled PP. The recycled PP of grade 3 contains the largest amount of polyethylene (PE). However, the lowest amount of PE is measured in the recycled PP of grade 54 . The recycled PP of grade 10 contains more heterogeneities than the recycled PP of grades 3 and 54 . Brome, Carbon and $\mathrm{CaCO}_{3}$ particles have been quantified in the recycled $\mathrm{PP}$ of grade 10 .

To obtain the different grades of recycled PP, a different amount have been added. However, the peroxide is not detected by physicchemical analysis. It is assumed that peroxide is completely consumed during the recycling process. However, we mentioned its presence in Table 1 with the terminology 'modified peroxide' in order to highlight its use during recycling process.

It is important to note that the crystallinity degree and molecular weight present in the Table 1 have been determined only on the PP phases of each material.

\subsection{Mechanical tests}

The mechanical properties of the recycled polypropylene are determined through unidirectional quasi-static tensile (Fig. 1-a) and 4-point bending tests (Fig. 1-b) according respectively to the standards ISO 527-2 (2012) and ISO 14,125 (1998). The experimental conditions are described in Table 2 . The letters ' $T$ ' and ' $F$ ' refer respectively tensile test and flexural (bending) test. The tensile test speeds were selected in order to have at least three different strain rates to study the influence of strain rate on the mechanical properties. Bending test speeds were selected in order to have the same strain rates as tensile tests leading to rigorous comparison between the tensile and flexural properties.

Tensile and bending tests are conducted on universal tensile/compression machine type Instron 3345 equipped with a load cell of $5 \mathrm{kN}$ capacities and a displacement transducer. For the tensile 
tests, a strain clamp extensometer type Instron 2630-102 has been set up in order to measure elastic properties (stiffness, yield strain and stress at yield) in the gauge length (central part) of the tensile specimens (Fig. 1-c). During test, we use an infrared thermometer type scans Temp 440 to detect the possible variation of temperature due to the deformation mechanisms.

For 4-points bending test, we have manufactured a suitable bending device for the universal tensile/compression device

Table 2

Experimental conditions of tensile and bending tests.

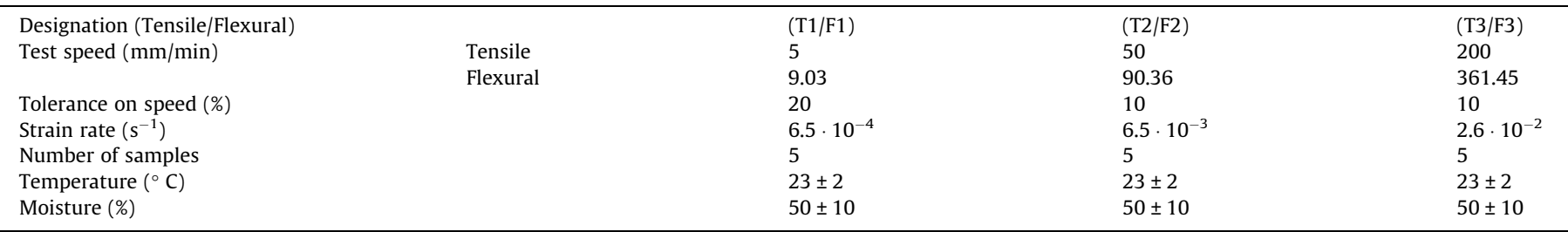

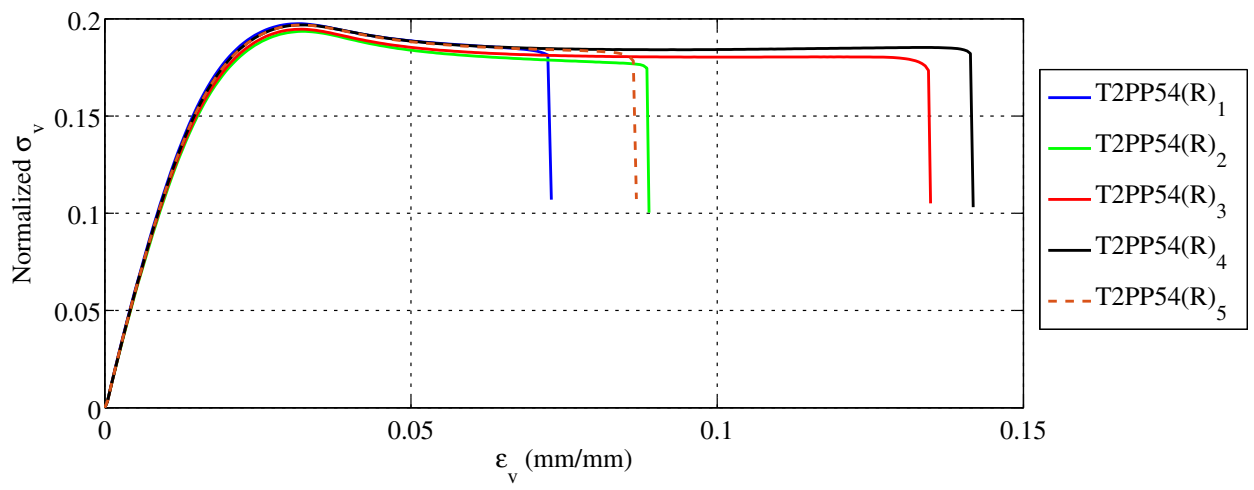

Fig. 2. Normalized true stress - true strain curves, tensile test, strain $=6.5 \cdot 10^{-3} \mathrm{~s}^{-1}$, PP54(R)

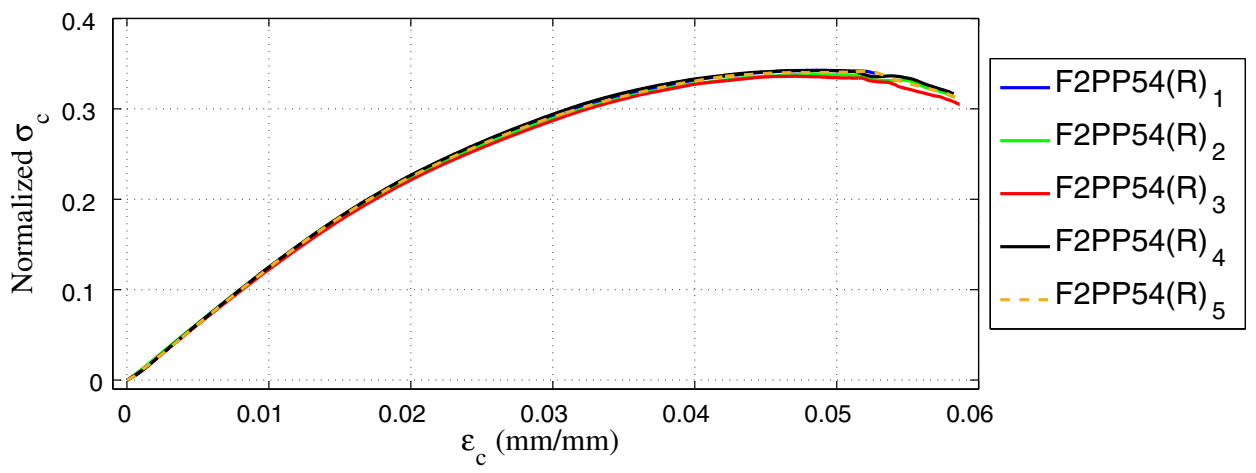

Fig. 3. Normalized corrected stress - corrected strain, bending test, strain rate $=6.5 \cdot 10^{-3} \mathrm{~s}^{-1}, \mathrm{PP} 54(\mathrm{R})$.

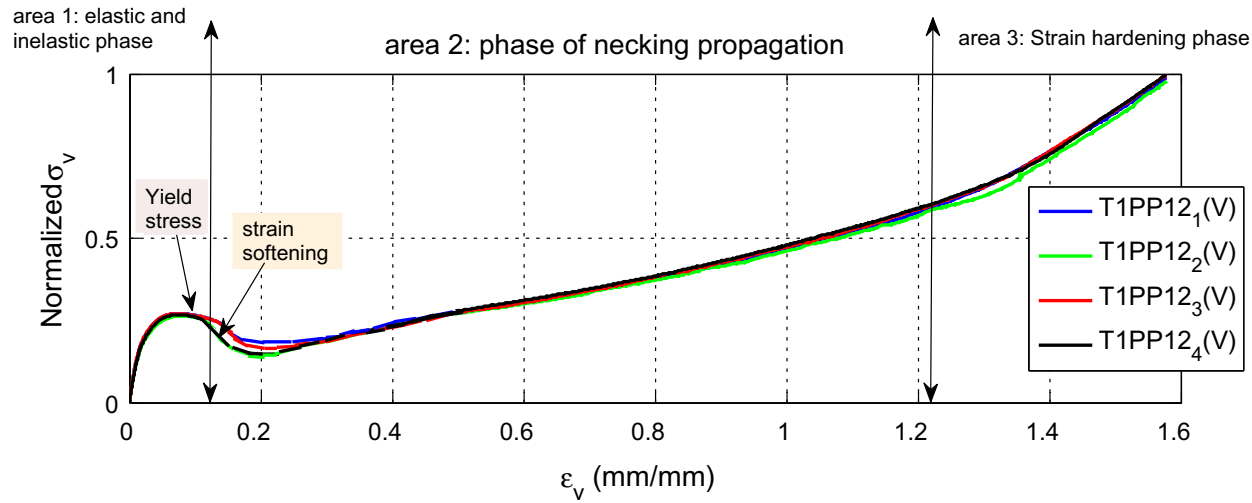

Fig. 4. Normalized true stress - true strain curves, tensile test, strain rate $=6.5 \cdot 10^{-4} \mathrm{~s}^{-1}, \mathrm{PP} 12(\mathrm{~V})$. 


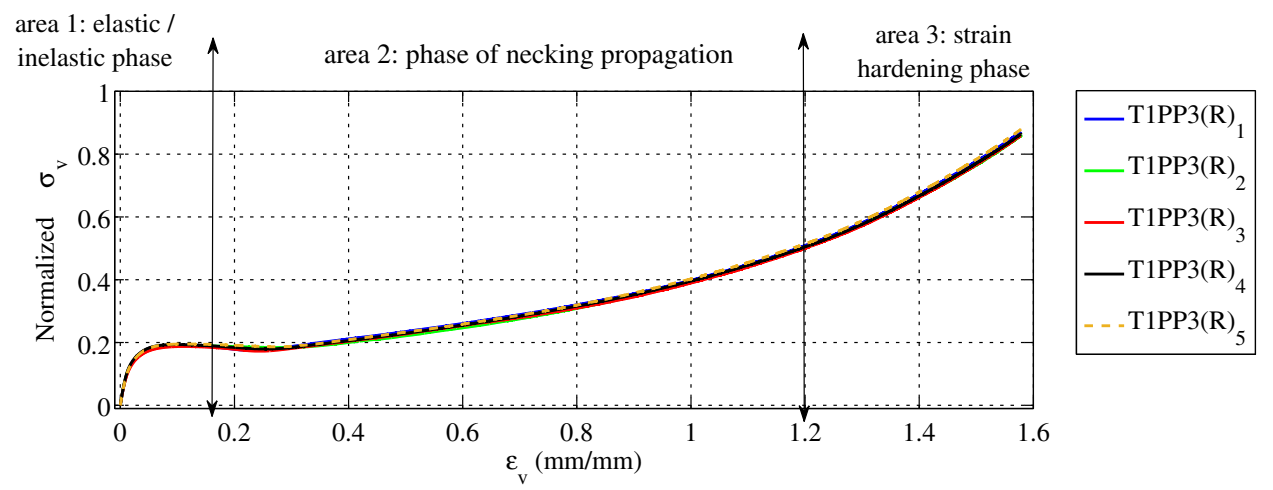

Fig. 5. Normalized true stress - true strain curves, tensile test, strain rate $=6.5 \cdot 10^{-4} \mathrm{~s}^{-1}, \mathrm{PP} 3(\mathrm{R})$.

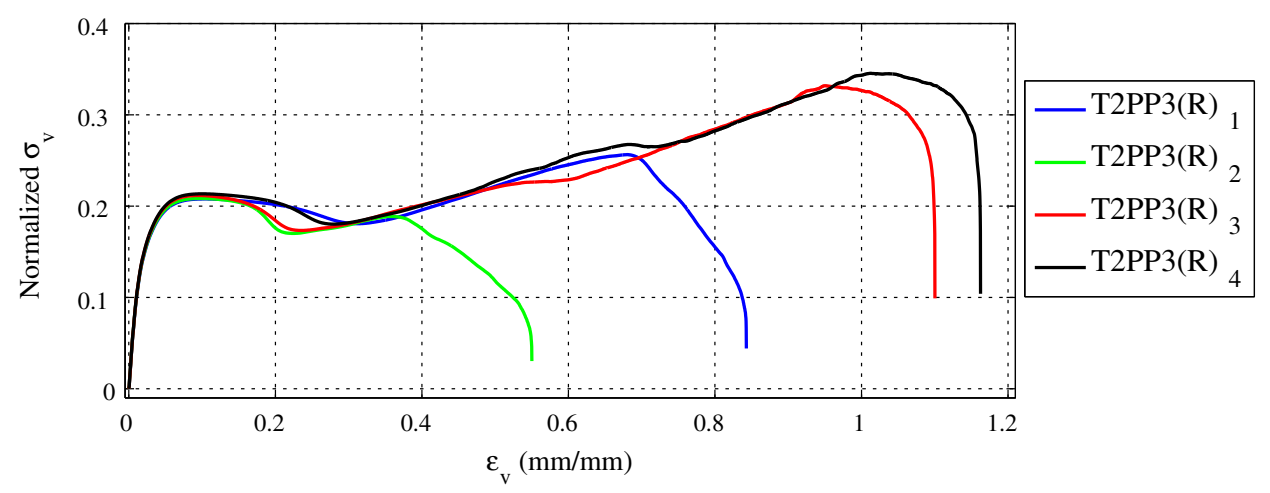

Fig. 6. Normalized true stress - true strain curves, tensile test, strain rate $=6.5 \cdot 10^{-3} \mathrm{~s}^{-1}, \mathrm{PP} 3(\mathrm{R})$.

Instron 3345. The 4-points bending test has been chosen because it can provide theoretically a pure bending between the loading spans in the case of small deformation (Fig. 1-b). The bending specimens (Fig. 1-c) have a rectangular shape with standardized dimensions (Class I, ISO 14,125). Unlike tensile tests which are conducted until the break of specimen, the bending tests are stopped when the specimen begin warping around the load spans (Fig. 1-b). Thus, the comparison between tensile and flexure properties will be conducted only on elastic properties.

In this work, $\boldsymbol{T} \boldsymbol{i} \boldsymbol{X}_{\boldsymbol{j}}$ (resp. $\boldsymbol{F i} \boldsymbol{X}_{\boldsymbol{j}}$ ) where $\boldsymbol{i}$ varies from 1 to 3 and $\boldsymbol{j}$ varies from 1 to $5 . \boldsymbol{T}$ (resp. $\boldsymbol{F}$ ) indicates a tensile test (resp. bending test) piloted with the $\boldsymbol{i}^{\text {th }}$ strain rate on the $\mathbf{j}^{\text {th }}$ specimen. $\boldsymbol{X}$ designates the tested material (PP3(R), PP10(R), PP54(R) or PP12(V)).

For industrial confidentiality purposes, the results of recycled and virgin polypropylene, presented in this paper, have been normalized to those of the virgin polypropylene as an example the

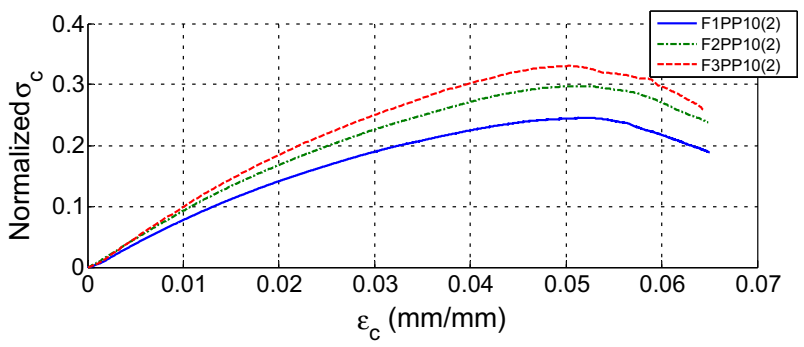

Fig. 8. Comparison of the corrected stress- corrected strain curves of the three strain rates (F1: $\left.6.5 \cdot 10^{-4} \mathrm{~s}^{-1}, \mathrm{~F} 2: 6.5 \cdot 10^{-3} \mathrm{~s}^{-1}, \mathrm{~F} 3: 2.6 \cdot 10^{-2} \mathrm{~s}^{-1}\right), \mathrm{PP} 10(\mathrm{R})$, bending test.

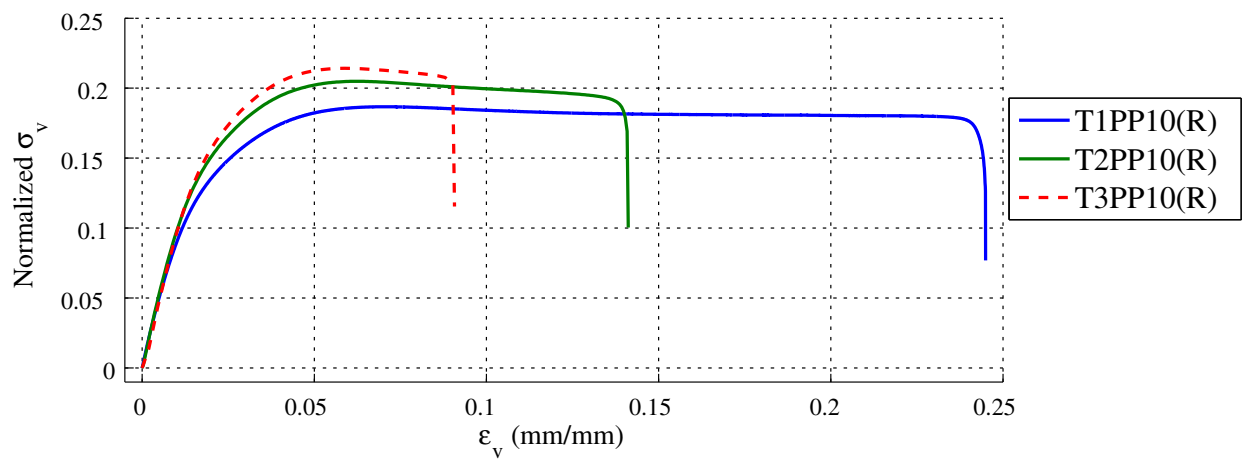

Fig. 7. Comparison of the true stress- true strain curves of the three strain rates (T1: $\left.6.5 \cdot 10^{-4} \mathrm{~s}^{-1}, \mathrm{~T} 2: 6.5 \cdot 10^{-3} \mathrm{~s}^{-1}, \mathrm{~T} 3: 2.6 \cdot 10^{-2} \mathrm{~s}^{-1}\right)$, PP10(R), tensile test. 
normalized mechanical property NP obtained from the specimen $\boldsymbol{T} \boldsymbol{i} \boldsymbol{X}_{\boldsymbol{j}}$ (resp. Fi $\boldsymbol{X}_{\boldsymbol{j}}$ ) is given by:

$N P_{T i X_{j}}=\frac{P_{T i X_{j}}}{\max _{j=1: 5}\left(P_{T i P P 12(V)_{j}}\right)}$

where $\boldsymbol{P}$ designates the mechanical properties determined through experimental tensile and bending tests (elastic modulus $E$, yield stress $\sigma_{y}$, etc.).

In this paper, normalized stresses are used for plotting stressstrain curves. Using Eq. (1), normalized stresses are calculated from

a

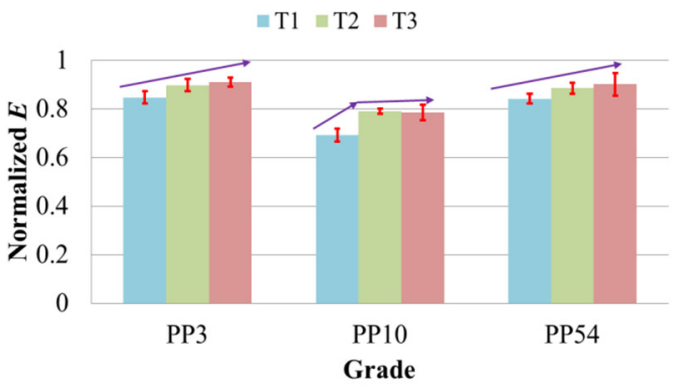

c

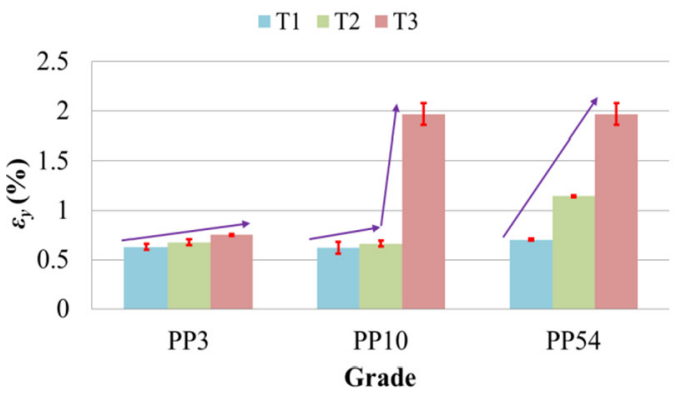

e

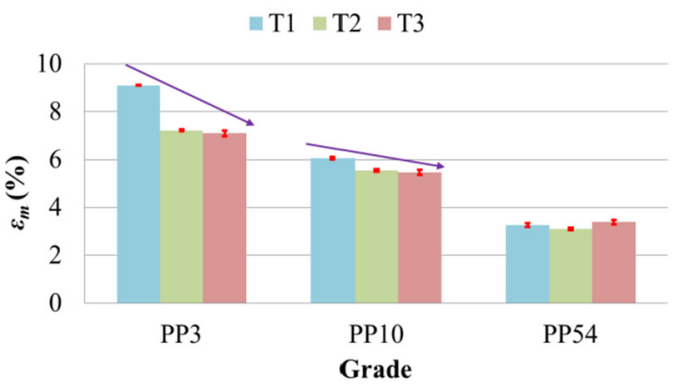

the true stress in the case of tensile tests and from the corrected stress in the case of bending tests. Normalized true stress-true strain curves are plotted for tensile tests (Figs. 2 and 4-6). For bending tests, corrected stress $\sigma_{c}$ and corrected strain $\varepsilon_{c}$ are calculated according to the standard ISO 14125 (Eq. (2) and Eq. (3)). Normalized corrected stress - corrected strain curves (Figs. 3 and 8) are then used to determine mechanical properties at large deformations for bending tests.

$\sigma_{c}=\frac{F L}{b h^{2}}\left(1+8.87\left(\frac{x}{L}\right)^{2}-7.04\left(\frac{x h}{L^{2}}\right)\right)$

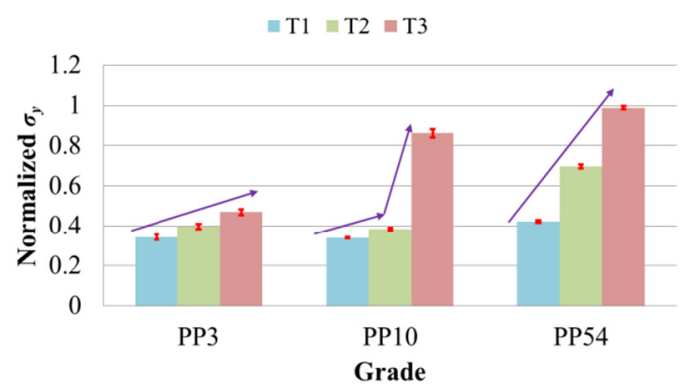

d

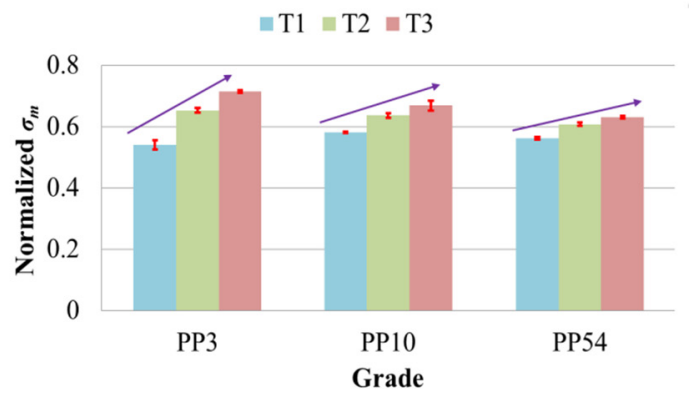

f

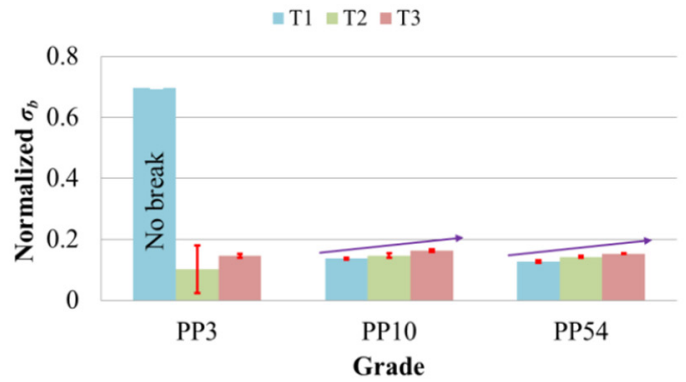

g

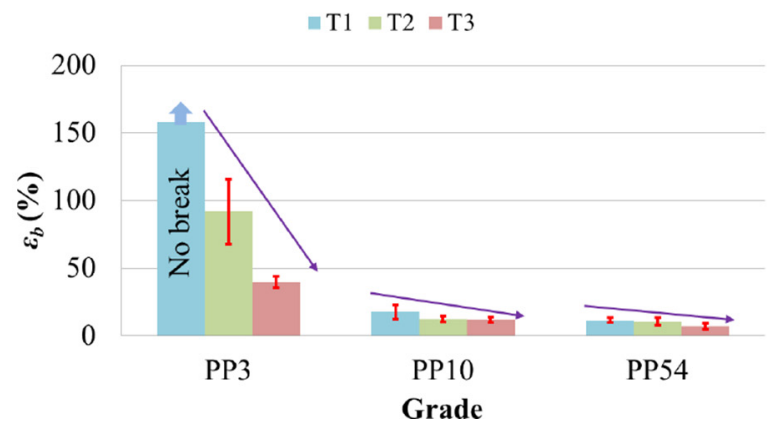

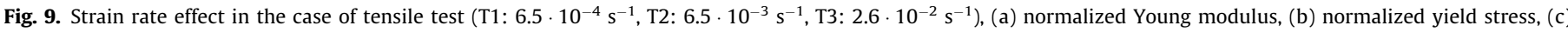
normalized strength, (d) strain at yield, (e) strain at strength, (f) break stress, (g) strain at break stress. 
$\varepsilon_{c}=\frac{h}{L}\left(4.7 \frac{x}{L}-14.39\left(\frac{x}{L}\right)^{3}+27.70\left(\frac{x}{L}\right)^{5}\right)$

where $\left\{\begin{array}{l}\sigma_{c}: \text { correctedstress } \\ \varepsilon_{c} \text { :correctedstrain } \\ F: \text { force }\end{array}\right.$ and $\left\{\begin{array}{l}L: \text { distancebetweenthesupportcylinders } \\ b: \text { specimenwidth } \\ h: \text { specimenthickness } \\ x: \text { displacementof theloadingcylinders }\end{array}\right.$.

True stress $\sigma_{v}$ and true strain $\varepsilon_{v}$ are given respectively by the Eqs. (4) and (5).

$\sigma_{v}=\frac{F}{b h}\left(1+\frac{x}{L}\right)$

$\varepsilon_{v}=\ln \left(1+\frac{x}{L}\right)$

where $\left\{\begin{array}{l}\sigma_{v}: \text { true stress } \\ \varepsilon_{v}: \text { true strain } \\ L: \text { specimen length }\end{array}\right.$ and $\left\{\begin{array}{l}b: \text { specimen width } \\ h: \text { specimen thickness. } \\ x: \text { displacement }\end{array}\right.$

a

$$
\varpi \mathrm{F} 1=\mathrm{F} 2=\mathrm{F} 3
$$

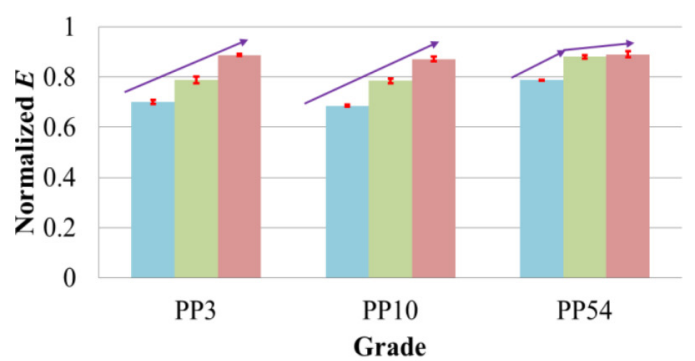

C

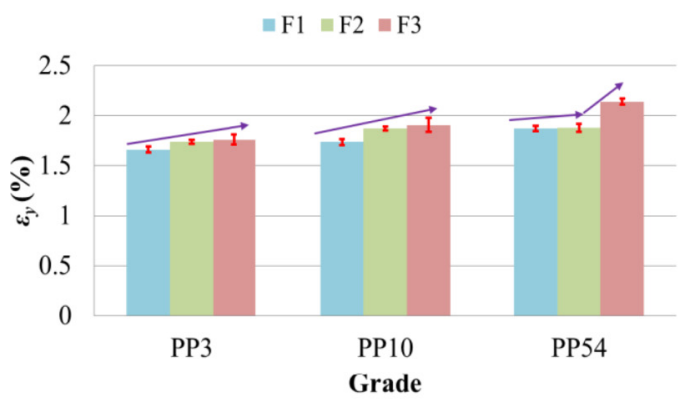

\section{Results and discussions}

\subsection{Strain-stress curves}

The Figs. 2-6 show typical stress-strain curves of recycled and virgin polypropylene in both bending and tensile tests with an elasto-visco-plastic behaviour. The viscoelastic behaviour of recycled polypropylene is highlighted during the measurement of the

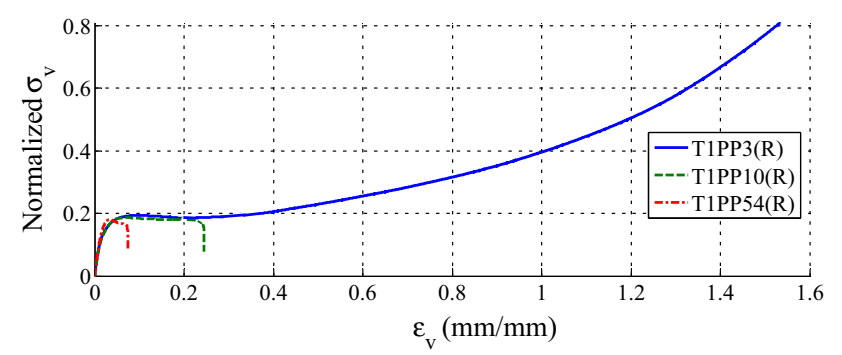

Fig. 11. Comparison of normalized true stress - true strain curves of the three references of recycled PP, strain $6.5 \cdot 10^{-4} \mathrm{~s}^{-1}$.

b

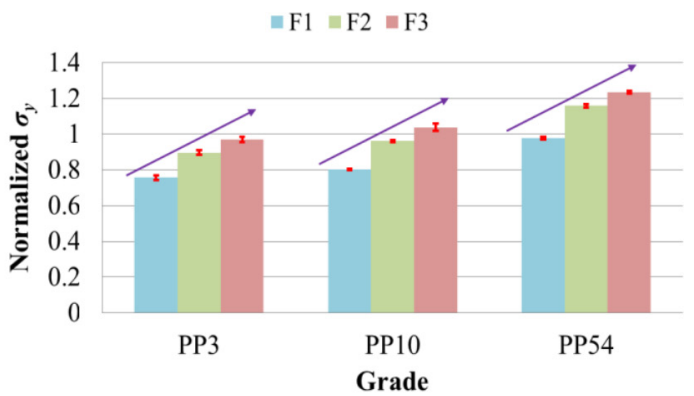

d

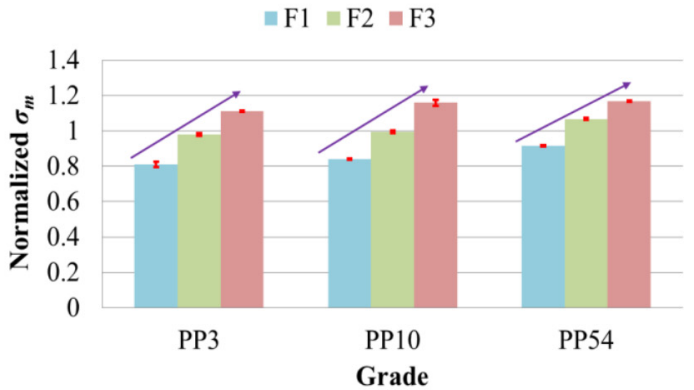

e

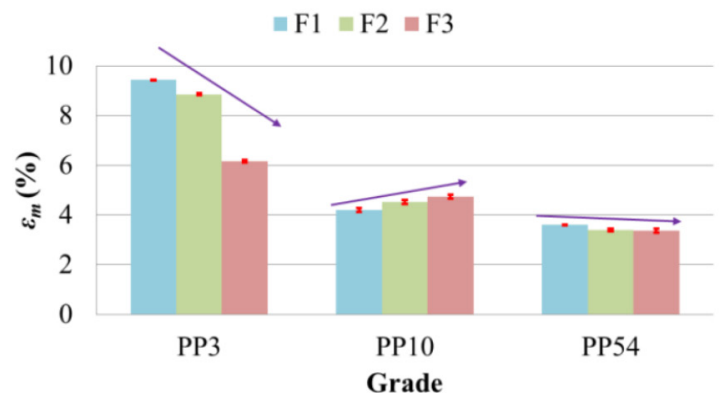

Fig. 10. Strain rate effect in the case of bending test (F1: $6.5 \cdot 10^{-4} \mathrm{~s}^{-1}, \mathrm{~F} 2: 6.5 \cdot 10^{-3} \mathrm{~s}^{-1}, \mathrm{~F} 3: 2.6 \cdot 10^{-2} \mathrm{~s}^{-1}$ ), (a) normalized Young modulus, (b) normalized yield stress, (c) strain at yield, (d) normalized strength, (e) strain at strength. 
deflection evolution after unloading of bending specimens. In fact, a rapid recovery was observed initially followed by a slow evolution of the deflection: the deflection decreases from $35 \mathrm{~mm}$ just before unloading specimen to $9 \pm 1 \mathrm{~mm}$ after in $1 \mathrm{~min}$ after testing. After 10 days, the measured deflection was between $6 \mathrm{~mm}$ and $7 \mathrm{~mm}$.

In the case of strain rate of $\mathrm{T} 1=6.510^{-4} \mathrm{~s}^{-1}$, the virgin polypropylene 'PP12(V)' highlights a typical tensile behaviour of semi-crystalline polypropylene (Fig. 4) (Bowden and Young, 1974; Detrez and Roland, 2008; Drozdov and Christiansen, 2003).
The normalized true stress-true strain of T1PP12(V) can be analysed in three areas. In the first area, the deformation is homogeneous and an increase of stress is observed up to moderate strain levels. A shear banding phenomena has been observed just before yield point. This shear bands are called Lüders bands (Bowden and Young, 1974; Detrez and Roland, 2008; Drozdov and Christiansen, 2003). After the yield point, a strain softening appears before the plasticity stage which is characterized by a quite large plateau (area 2). The deformation becomes nonhomogeneous and the necking begin propagate along the length of test specimen a

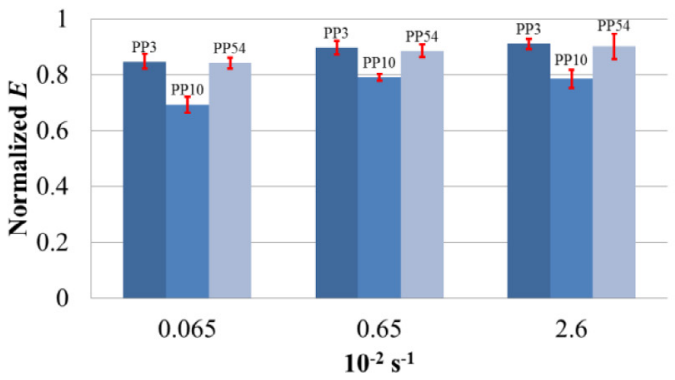

c

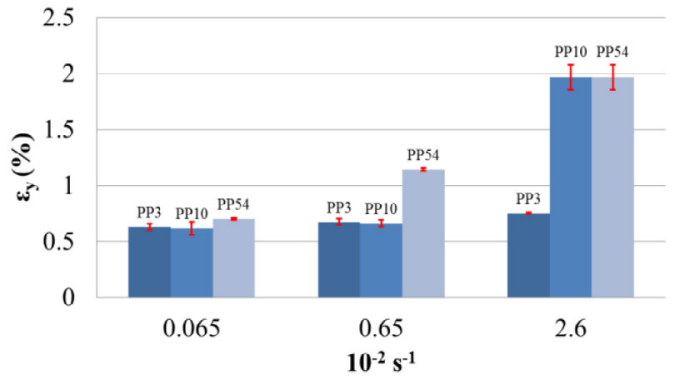

e

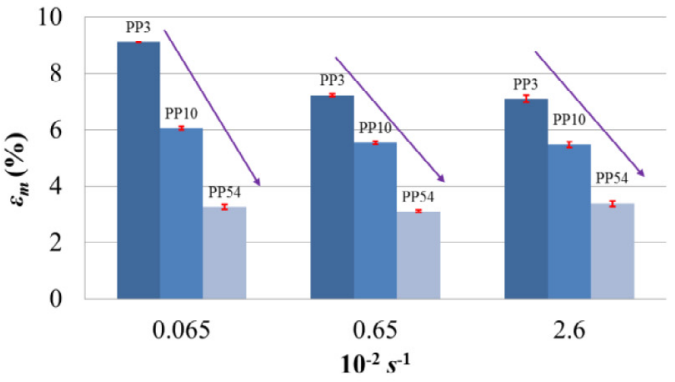

b

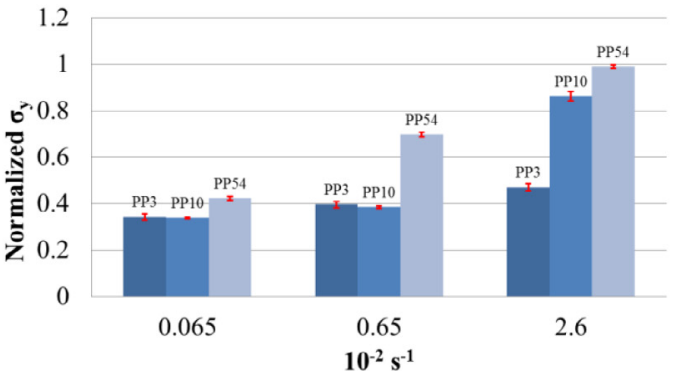

d

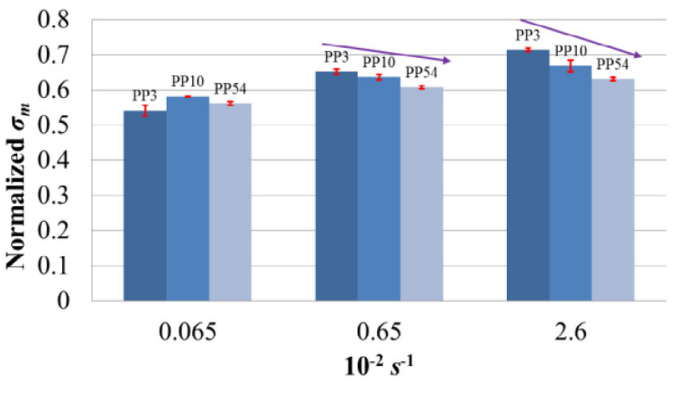

$\mathrm{f}$

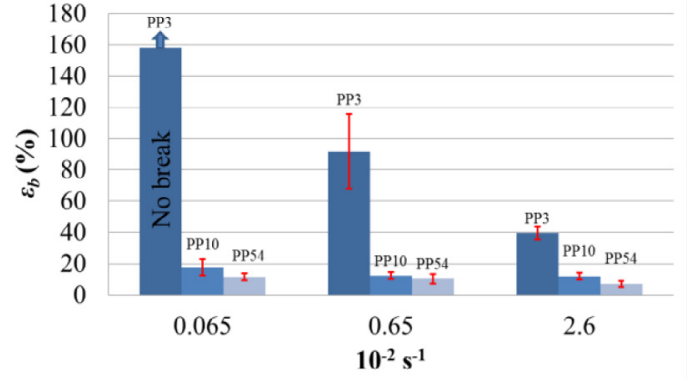

g

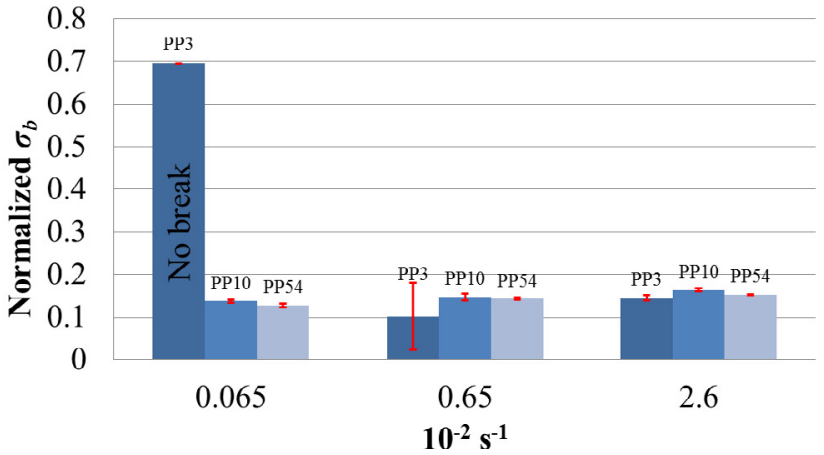

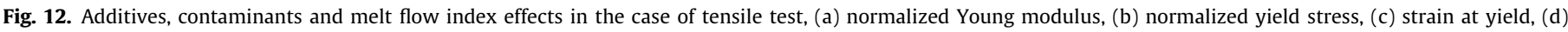
normalized strength, (e) strain at strength, (f) strain at break stress, (g) break stress. 
(Bowden and Young, 1974; Detrez and Roland, 2008; Drozdov and Christiansen, 2003). Finally, strain hardening takes place up to large strain level (area 3). The deformation becomes again homogeneous (Bowden and Young, 1974; Detrez and Roland, 2008).

In the case of strain rate $\mathrm{T} 1=6.510^{-4} \mathrm{~s}^{-1}$, the displacement limits of tensile device is reaching without the break of the recycled PP of grade 3 . However, in the case of strain rate T3 $=2.6$ $10^{-2} \mathrm{~s}^{-1}$, the break of recycled PP of grade 3 is obtained without large deformation. The break of PP3(R) is also reached in the case of strain rate $\mathrm{T} 2=6.510^{-3} \mathrm{~s}^{-1}$ and dispersed values of stress and strain at break are obtained (Fig. 6). The typical tensile behaviour of semi crystalline polypropylene has been observed for recycled $\mathrm{PP}$ of grade 3 'PP3' in the case of strain rates $6.510^{-4} \mathrm{~s}^{-1}$ (T1) and $6.510^{-3} \mathrm{~s}^{-1}$ (T2) (Figs. 5 and 6). However, the yield point was less pronounced than for the virgin PP. Fibrillary morphology has been observed in the hardening area of recycled PP3. A local heating in the vicinity of rupture zone at the strain rate of $\mathrm{T} 2$ has been detected for the recycled $\mathrm{PP} 3\left(35^{\circ} \mathrm{C}\right.$ in the vicinity of the rupture zone against $23^{\circ} \mathrm{C}$ on the rest of specimen).

The mechanical properties determined through experimental tensile and bending tests are the elastic modulus $E$, the yield stress $\sigma_{y}$, the yield strain $\varepsilon_{y}$, the maximum stress (strength) $\sigma_{m}$ and the a

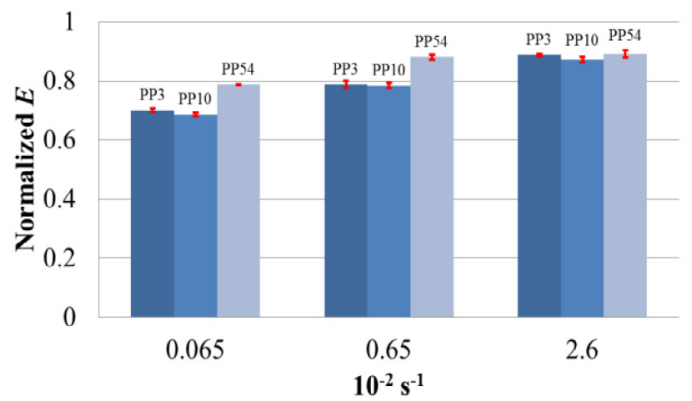

C

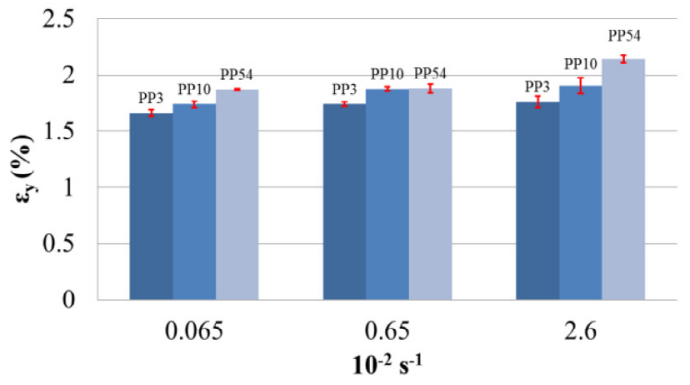

b

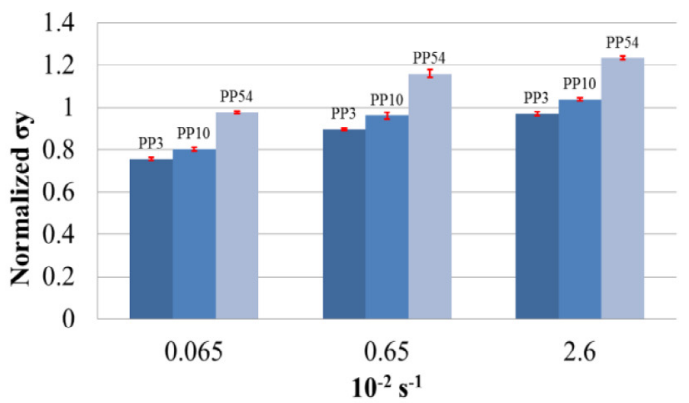

d

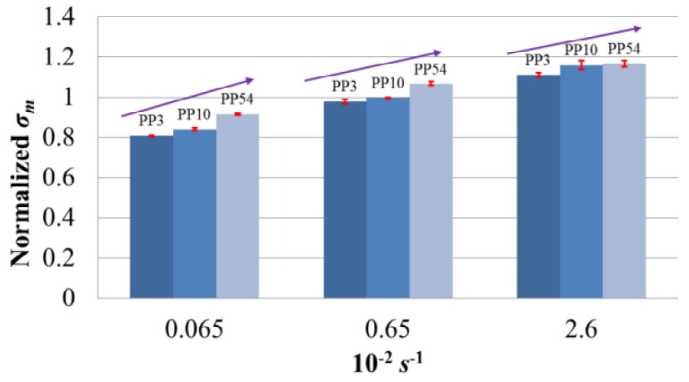

$\mathrm{e}$

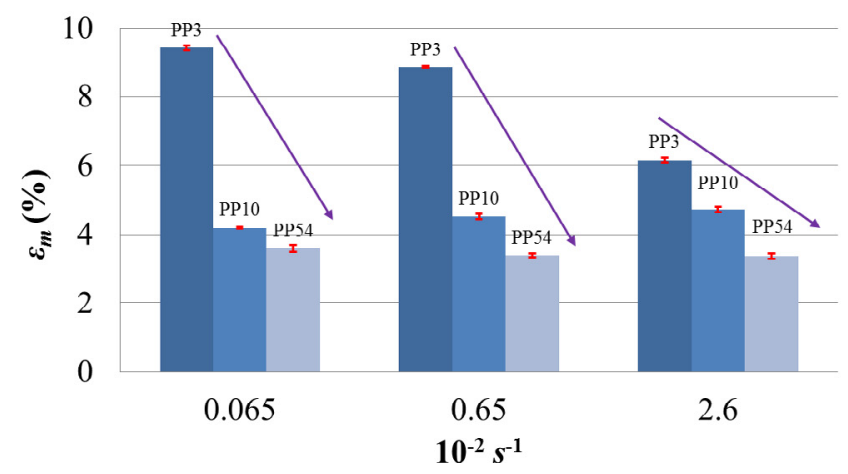

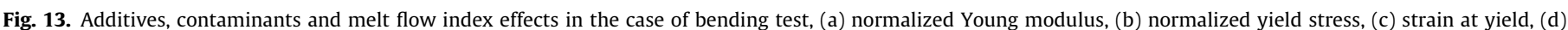
normalized strength, (e) strain at strength.

Table 3

Comparison between tensile and bending properties.

\begin{tabular}{|c|c|c|c|}
\hline & Tensile test & Bending test & Comparison \\
\hline Young modulus & $E^{P P 10(R)}<E^{P P 3(R)} \leqslant E^{P P 54(R)}$ & $E^{P P 10(R)}<E^{P P 3(R)} \leqslant E^{P P 54(R)}$ & Similar \\
\hline Yield stress & $\sigma_{y}^{P P 3(R)} \leqslant \sigma_{y}^{P P 10(R)}<\sigma_{y}^{P P 54(R)}$ & $\sigma_{y}^{P P 3(R)}<\sigma_{y}^{P P 10(R)}<\sigma_{y}^{P P 54(R)}$ & Similar \\
\hline Strain at yield & $\varepsilon_{y}^{P P 3(R)} \leqslant \varepsilon_{y}^{P P 10(R)} \leqslant \varepsilon_{y}^{P P 54(R)}$ & $\varepsilon_{y}^{P P 3(R)} \leqslant \varepsilon_{y}^{P P 10(R)} \leqslant \varepsilon_{y}^{P P 54(R)}$ & Similar \\
\hline Strength & $\sigma_{m}^{P P 54(R)} \leqslant \sigma_{m}^{P P 10(R)} \leqslant \sigma_{m}^{P P 3(R)}$ & $\sigma_{m}^{P P 3(R)} \leqslant \sigma_{m}^{P P 10(R)}<\sigma_{m}^{P P 54(R)}$ & In contradiction \\
\hline Strain at strength & $\varepsilon_{m}^{P P 3(R)} \leqslant \varepsilon_{m}^{P P 10(R)} \leqslant \varepsilon_{m}^{P P 54(R)}$ & $\varepsilon_{m}^{P P 3(R)} \leqslant \varepsilon_{m}^{P P 10(R)} \leqslant \varepsilon_{m}^{P P 54(R)}$ & Similar \\
\hline
\end{tabular}



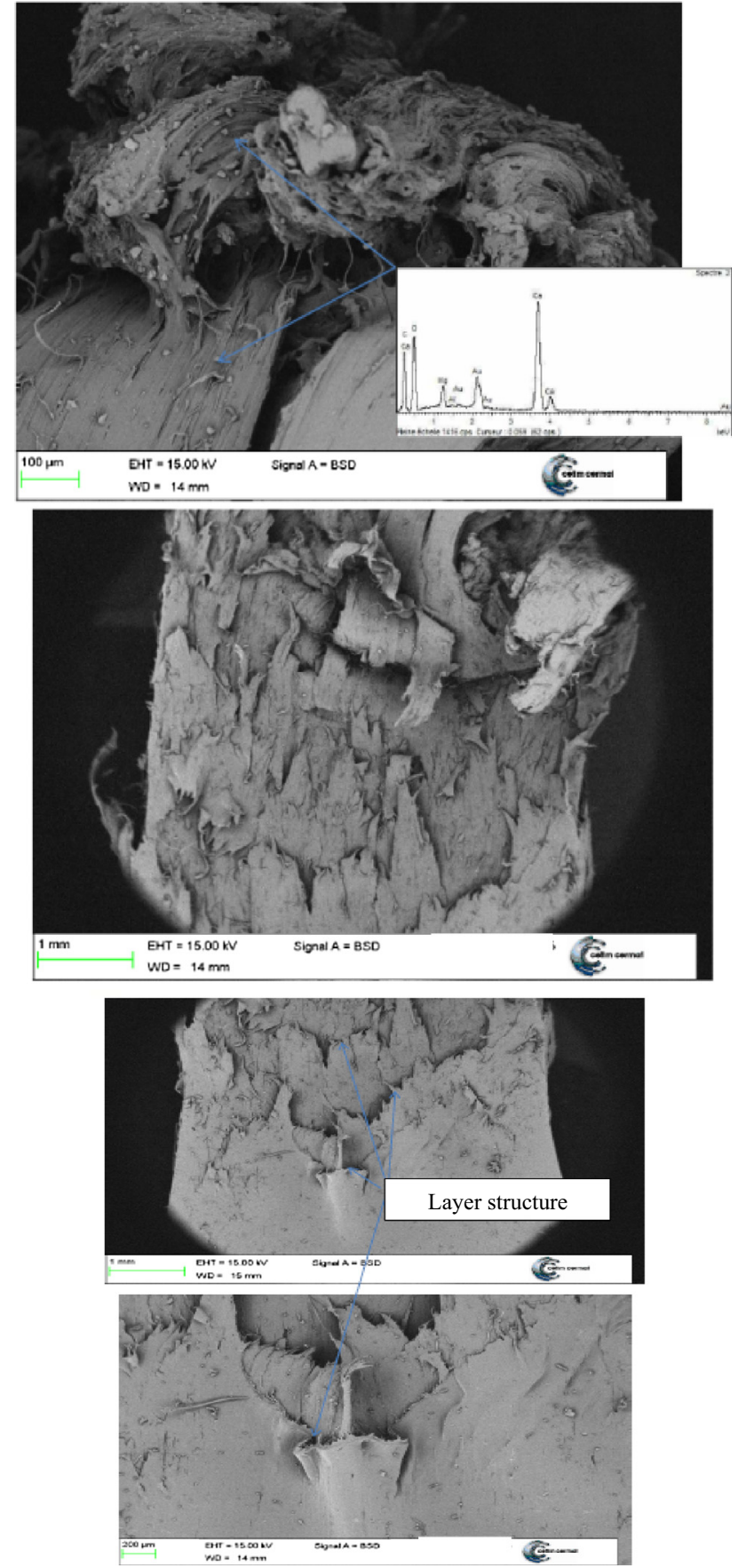

Fig. 14. Microscopic observations of PP3(R) fracture.

strain at maximum stress $\varepsilon_{m}$. The stress at break $\sigma_{b}$ and the elongation at break $\varepsilon_{b}$ are only determined through the tensile tests.

Despite the waste origin of the samples (Figs. 2-6) a repeatable tests has been highlighted by the weak dispersion observed in the determination of the mechanical properties. With the exception of break properties, the dispersion of the identified properties is lower than $5 \%$ of their average values.

\subsection{Strain rate effects}

The Figs. 7 and 8 show a dependence of the mechanical properties of recycled PP to the strain rate. In both tensile and bending tests, strength appears more sensitive to strain rate than Young modulus. Fig. 7 shows that strain at break decreases when strain rate increases. For better observation of the strain rate sensitivity, two histograms have been plotted in both tensile and bending tests (Figs. 9 and 10).

Overall, we can conclude that there is an increase of elastic properties of recycled PP in both tensile and bending tests when the strain rate increases. The increase of elastic modulus (Figs. 9a and 10-a) can be related to the reduction of molecular chain mobility which is due to the increasing of the strain rate. A secondary molecular process can be the origin of the increase of the yield stress (Figs. 9-b and 10-b) (Chen et al., 1999; Matadi et al., 2011). The experimental investigation shows also the increase of the strain at yield stress (Figs. 9-c and 10-c). The strain at maximum stress of recycled PP with grade 3 decreases in both tensile and bending tests with the increase of the strain rate (Figs. 9-e and 10-e). However, for the recycled PP with grade 10, the strain at maximum stress decreases in the case of tensile tests (Fig. 9-e) and increases in the case of bending tests with the increase of the strain rate (Fig. 10-e). In both tensile and bending tests, the effect of the strain rate on the strain at maximum stress of recycled PP with grade 54 is very small (Figs. 9-e and 10-e). However, the strain at maximum stress seems to decrease with the strain rate in the case of bending. We cannot conclude in the case of tensile tests. For the break properties, the elongation at break decreases with the increase of the strain rate (Fig. 9-f). In the case of strain rate $\mathrm{T} 1=6.510^{-4} \mathrm{~s}^{-1}$, the displacement limits of tensile device is reached without the break of the recycled PP of grade 3 . However, in the case of strain rate $\mathrm{T} 3=2.610^{-2} \mathrm{~s}^{-1}$, the break of recycled PP of grade 3 is obtained without large deformation. PP3(R) in the case of $\mathrm{T} 3$ becomes brittle comparing to the case of T1. The deformation mechanisms in the case of strain rate $\mathrm{T} 1$ and in the case of strain rate $\mathrm{T} 3$ are different (see Section 3.3). In the case of strain rate $\mathrm{T} 2=6.510^{-3} \mathrm{~s}^{-1}$ which is between $\mathrm{T} 1$ and T3, the mechanisms of deformation of $\mathrm{T} 1$ and $\mathrm{T} 3$ contribute at the same time. A local heating in the vicinity of rupture zone at the strain rate $\mathrm{T} 2$ has been detected for recycled PP3 (Fig. 15-b). The contribution of different deformation mechanisms at same time and the local heating explain the dispersion of stress and strain at break of PP3(R) at T2 (Fig. 9-f and -g). For recycled PP with grade 10 and 54 (Fig. 9$\mathrm{g})$, the stress at break seems to increase with the strain rate.

To complete our study of the strain rate effect on the mechanical properties of the recycled PP, it is interesting to consider the perspective of the dynamic tensile behaviour through Hopkinson bar tests.

\subsection{Additive, contaminant and melt flow index effects}

The polypropylene are usually classified according to their melt flow index (MFI = grade). The Melt flow index is a measure of the a

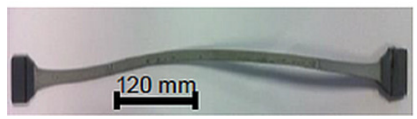

b

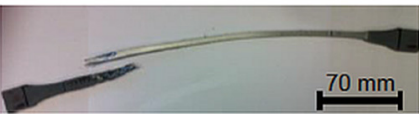

C

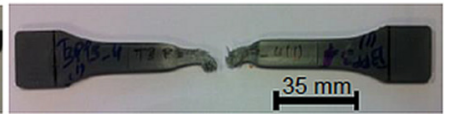

Fig. 15. PP3(R) specimen after tensile test, (a) T1: $6.5 \cdot 10^{-4} \mathrm{~s}^{-1}$, (b) $\mathrm{T} 2: 6.5 \cdot 10^{-3} \mathrm{~s}^{-1}$, (c) T3: $2.6 \cdot 10^{-2} \mathrm{~s}^{-1}$. 
ease of flow of melted plastics and represents a typical index for quality control of thermoplastics. The peroxide is generally by suppliers to control melt flow index (grade) of PP. It acts as a polymer chain scission agent: shorter are the chains, lower are their molecular weights and higher is the melt flow index.
For the semi-crystalline iso-tactic polypropylene, the scission of polymer chains is usually linked with an increase of the crystallinity rate which induces an increase of stiffness. The crystalline arrangement prevents the rotation of the chain branches therefore inducing an increase of the stress yield (Aurrekoetxea et al., 2001).
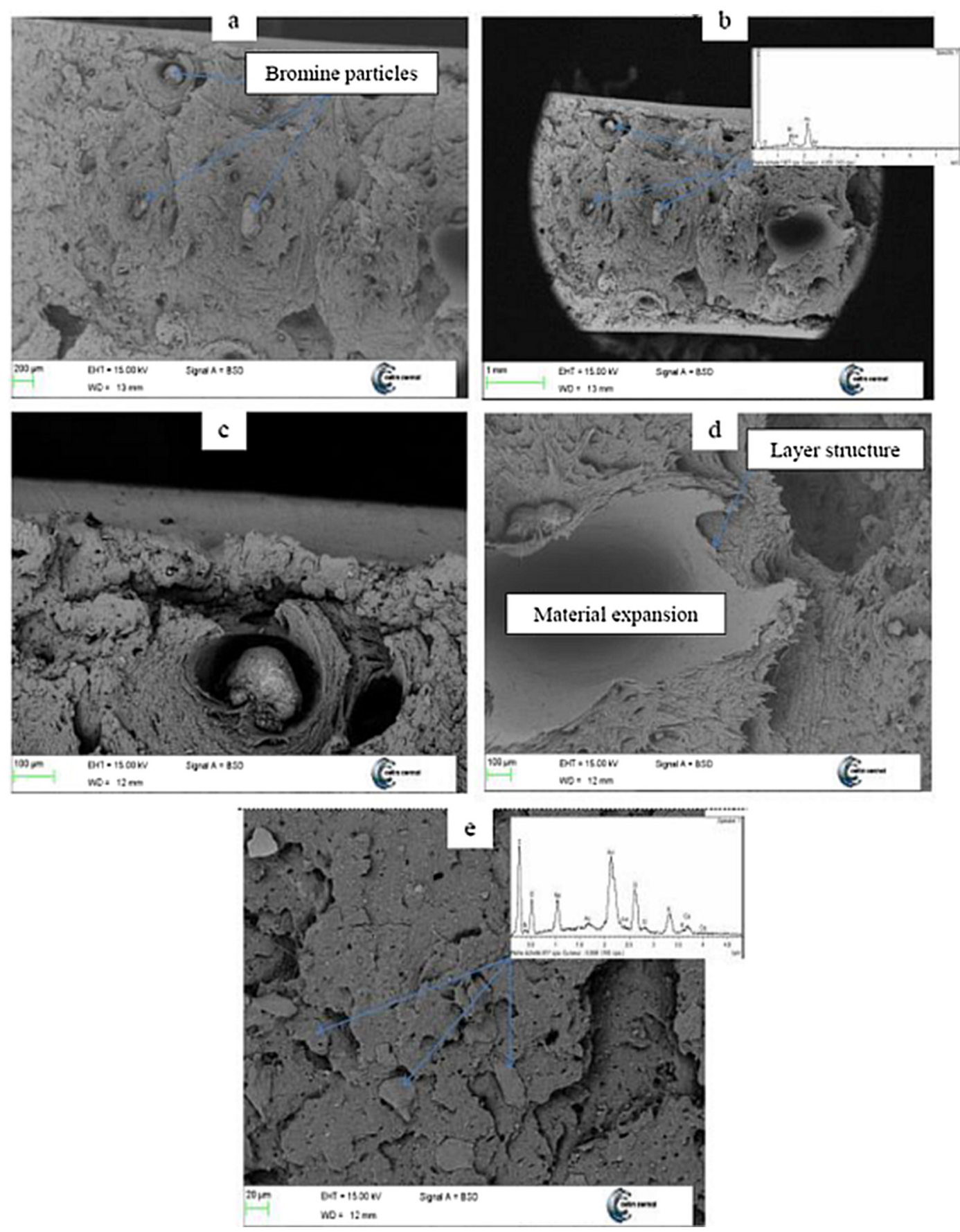

Fig. 16. Microscopic observations of PP10(R) fracture.

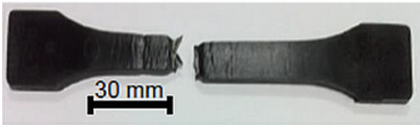

b

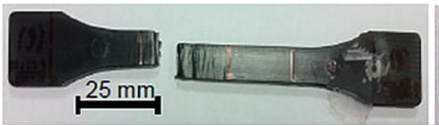

C

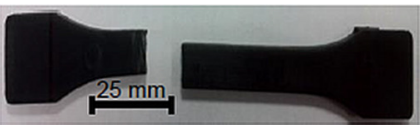

Fig. 17. $\mathrm{PP} 10(\mathrm{R})$ specimen after tensile test, (a) $\mathrm{T} 1: 6.5 \cdot 10^{-4} \mathrm{~s}^{-1}$, (b) $\mathrm{T} 2: 6.5 \cdot 10^{-3} \mathrm{~s}^{-1}$, (c) T3: $2.6 \cdot 10^{-2} \mathrm{~s}^{-1}$. 
So, for neat polymer material, MFI (grade) is an important physical measure which is related indirectly to mechanical properties.

The MFI (grade) of the three references of recycled polypropylene considered in this study is controlled through the use of modified peroxide. Obviously, the molecular weight decreases with the MFI (Table 1). As described above, we should expect that the crystallinity degree increases and as a result the Young modulus increases with MFI. However, Table 1 shows that the crystallinity degree (38\% for grade 3 and 41\% for grades 10 and 54) is almost the same with the increasing of MFI. The contaminants and additives in the three grade of recycled polypropylene reduce the mobility of polymer chains inducing a similar crystallinity. If we consider only the analysis of material crystallinity, Young's modulus and yield stress of grades 10 and 54 should be higher than those of grade 3. Figs. 12 and 13 show that recycled PP of grade 54 presents the highest Young modulus and yield stress in both tensile and bending tests. However, the recycled PP of grade 10 is not in accord with the expectations for material's crystallinity effect
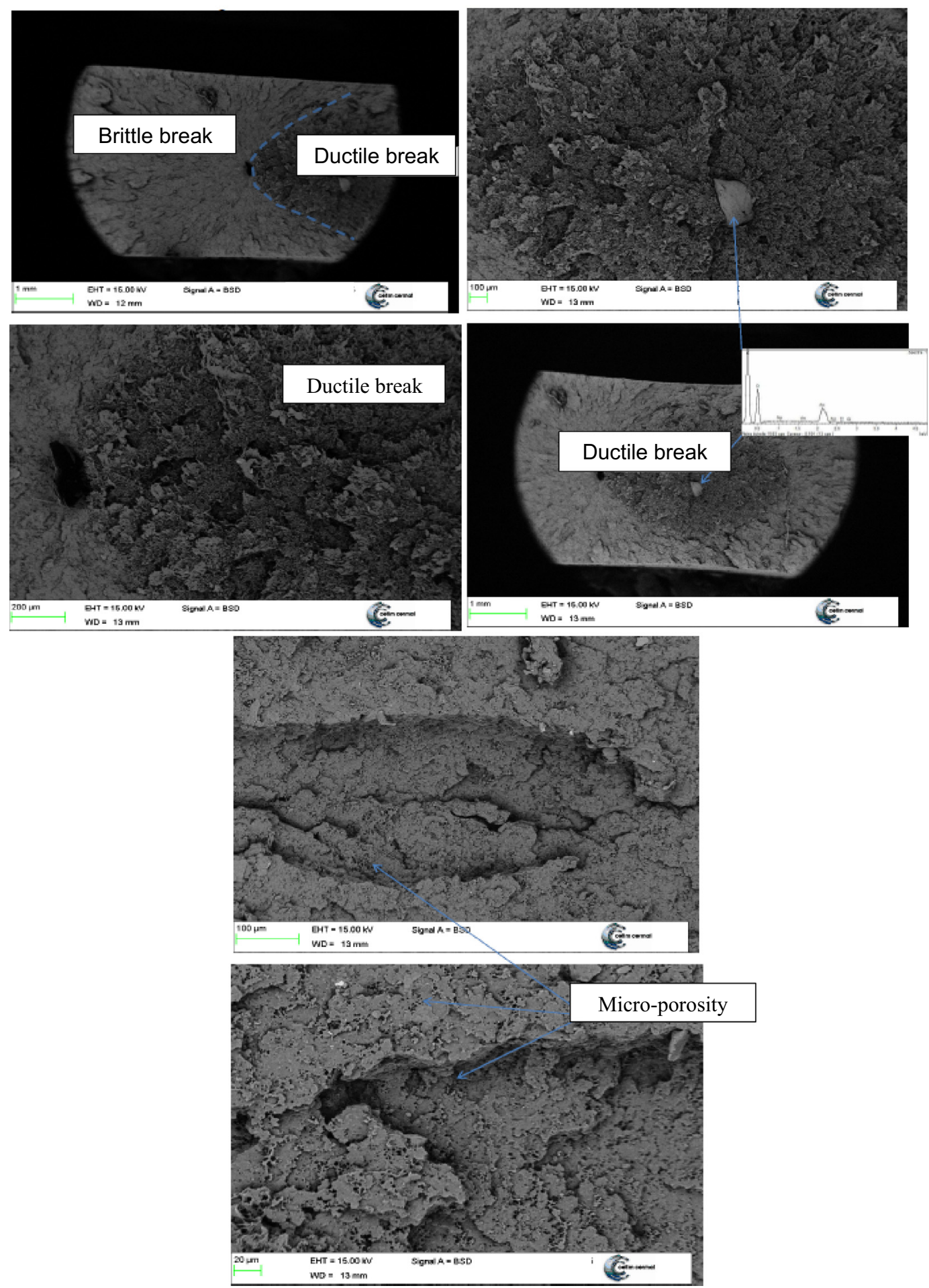

Fig. 18. Microscopic observations of PP54(R) fracture. 
analysis: in both tensile and bending tests, PP10(R) has the lowest Young modulus (Figs. 12-a and 13-a). To explain this contradiction between the crystallinity effects and the experimental results of Young modulus and yield stress of grade 10, we are interested in analysing the effects of additives/contaminants on the mechanical properties of recycled PP (Figs. 11-13).

In the literature, it has been shown that the addition of PE up to $50 \%$ induces a significant decrease of the Young modulus and the yield stress comparing to neat PP (Bertin and Robin, 2002). Thus, the smallest quantity of PE contained in the recycled PP of grade 54 contributes to its highest elastic properties. By comparing the PE quantities in the recycled PP of grades 3 and 10, we can explain the lowest yield stress of PP3(R) in the case of bending test (Fig. 13b). However PE cannot explain the lowest Young modulus of PP10 (R) (Figs. 12-a and 13-a). $\mathrm{CaCO}_{3}$ and carbon particles are generally added to increase rigidity and impact resistance of polypropylene (Zuiderduin et al., 2003). They induce an increase of yield stress. The presence of $5 \%$ of $\mathrm{CaCO}_{3}$ in the recycled PP of grade 3 in comparison with $1.8 \%$ in the $\mathrm{PP} 10(\mathrm{R})$ may explain the lower elastic modulus of PP10(R) in both tensile and bending test. The presence of carbon and bromine particles within very small quantities in PP10(R) is not sufficient to reverse the experimental tend between PP3(R) and PP10(R).

For a given strain rate, tensile strength increases with the melt flow index, however, bending strength decreases while increasing grade. In bending test the top surface and the bottom surface of specimens are subject respectively to compression and tensile charges. We attribute the differences between tensile and bending properties of the recycled PP (Table 3 ) to the compression behaviour. It will therefore be interesting in perspective to study the compression properties of the recycled PP.

Despite the dispersion of the break properties, the experimental results show that the strain at break decreases with the grade of recycled PP (Fig. 12-f). The scission of polymers chains by adding peroxide explain the brittle failure observed in the recycled PP of grade 54 (Fig. 18). The presence of PE in a quantity less than $50 \%$ involves usually a significant reduction in the strain at break (Bertin and Robin, 2002): For our recycled PP, the PE effect on the strain at break seems to be less important than the peroxide effect (PE don't reverse the effect of peroxide on the strain at break).

The analysis of the combined effects of additives, contaminants and MFI shows that contrary to neat polypropylene, MFI is not sufficient to estimate the mechanical properties of recycled PP which contain contaminants and additives. Contaminants and additives have an important impact on mechanical properties even more than the MFI.

\subsection{Analysis of failure mechanisms}

For PP12(V), the main deformation mechanisms observed during tensile test are in according with the literature(Bowden and Young, 1974; Detrez and Roland, 2008; Drozdov and Christiansen, 2003):

- homogenous elastic and inelastic deformation until yield stress, - start necking and whitening (non-homogeneous deformation),

- propagation of necking along specimen gauge length,

- hardening and fibrillation until break.

Fig. 14 shows the microscopic observation of PP3(R) fracture. Many small particles of $\mathrm{CaCo} 3$ have been detected. Due to the presence of $\mathrm{PE}$, the $\mathrm{PP} 3(\mathrm{R})$ presents a layer structure.

The necking propagation depends on strain rate (Fig. 15). In fact, for the strain rates $\mathrm{T} 1$ and $\mathrm{T} 2$, the necking propagation reaches all gauge length of specimen before hardening. A local heating in the vicinity of rupture zone at the strain rate $\mathrm{T} 2$ has been detected for the recycled PP3 (Fig. 15-b). The fibrillation is clearer in the case of strain rate T2 than T1. For the strain rate of T1, we haven't reached the break of PP3(R). In case of T3, the fracture by fibrillation and layer delamination is initiated before the necking propagation along all specimen length (Fig. 15-c).

The post mortem analysis of PP10(R) fracture highlights the presence of large rigid particles. They correspond to the bromine derivatives (Fig. 16-a) and CaCO3 (Fig. 16-b and -c). A layer structure has been also observed in the case of PP10(R). However it is less marked than the PP3(R) structure.

The rigid particles can act as toughness agent or as structural defects which initiate material break depending to aspect ratio (Zuiderduin et al., 2003). The dimension ratio of the rigid particles in PP10(R) implies a stress concentration around particles and particle debonding which initiate failure (Fig. 16-c).

At the lowest strain rate, due to particle presence, a hole is observed (without microscopy) in the specimen after yield stress. This cavity continues propagation along the specimen width and it is accompanied by the delamination of the internal layers (Fig. 17-a). For the strain rates T2 and T3, a ductile failure has been detected (Fig. 17-b and -c). Fig. 16-d show a material expansion which is due to thermal effect in the vicinity of rupture zone (Zuiderduin et al., 2003).

PP54(R) contains a small quantity of PE. For this purpose, the PP54(R) has a structure more homogeneous than those of PP3(R) and PP10(R). From Fig. 18 we can easily distinguish two different zones of break: the first one corresponds to brittle break however the second one shows a ductile break around organic particles. The micro-porosity observed in the recycled PP of grade 54 is probably due to recycling process. This micro-porosity leads to a brittle behaviour. Same mechanisms of deformation in PP54(R) are detected for the strain rates T1, T2 and T3.

\section{Conclusions}

The tensile and bending tests conducted in this work on three grades of recycled PP which contain additives and contaminants in different strain rates highlighted the dependence of mechanical properties to strain rate as well as to melt flow index, additives and contaminants. The analysis of the their combined effects shows that contrary to neat polypropylene, MFI is not sufficient to estimate the mechanical properties of recycled PP which contain contaminants and additives. Contaminants and additives have an important impact on mechanical properties even more than the MFI. In both tensile and bending tests, Young's modulus, stress yield and the strength increases with strain rate. The strength is more sensitive to strain rate than Young's modulus. The strain at break decreases when strain rate increases. The comparison with virgin PP has shown that the mechanical properties of recycled PP depend not only to its melt flow index but also to the complex effects of the contaminants contained in the recycled PP from waste origin and additives added by suppliers. The Generally, $\mathrm{CaCO}_{3}$ particles and rigid fillers increase Young's modulus and yield stress. The rigid particles can act as toughness agent or as structural defects which initiate material break depending to its microstructures. Adding Peroxide during recycling process allows control the melt flow index of recycled PP by modifying microstructures. The deformation mechanisms of recycled PP depend on contaminants, additives and recycling process. The additives added by suppliers and the developed homogenization process during recycling allow obtaining repeatable mechanical characteristics despite the waste origin of the recycled PP. Despite the waste origin of the samples, repeatable tensile and bending tests have been obtained. It highlighted by the weak dispersion 
observed in the determination of the mechanical properties. With the exception of break properties, the dispersion of the identified properties is lower than $5 \%$ of their average values.

\section{Acknowledgments}

The authors acknowledge the financial support provided by 'BPI France', Strasbourg Euro metropole' and the region comities ('Région d'Alsace', 'Région de Bourgogne-Franche-Comté') to conduct this research. The authors also thank all industrial contributors 'Paprec Plastique', 'Plastiform' and 'Airepur industries'.

\section{References}

Ai Wah, C., Yub Choong, L., Seng Neon, G., 2000. Effects of titanate coupling agent on rheological behaviour, dispersion characteristics and mechanical properties of talc filled polypropylene. Eur. Polym. J. 36, 789-801. doi: 10.1016/S0014-3057 (99)00123-8.

Aurrekoetxea, J., Sarrionandia, M.A., Urrutibeascoa, I., Maspoch, M.L., 2001. Effects of recycling on the microstructure and the mechanical properties of isotactic polypropylene. J. Mater. Sci. 36, 2607-2613. https://doi.org/10.1023/ A:1017983907260.

Bahlouli, N., Pessey, D., Ahzi, S., Rémond, Y., 2006. Mechanical behavior of composite based polypropylene: recycling and strain rate effects. J. Phys. IV Fr. 134, 1319-1323. https://doi.org/10.1051/jp4:2006134200.

Bertin, S., Robin, J.-J., 2002. Study and characterization of virgin and recycled LDPE/ PP blends. Eur. Polym. J. 38, 2255-2264. https://doi.org/10.1016/S0014-3057 (02)00111-8.

Bowden, P.B., Young, R.J., 1974. Deformation mechanisms in crystalline polymers. J. Mater. Sci. 9, 2034-2051. https://doi.org/10.1007/bf00540553.

Brandrup, J., 1996. Recycling and Recovery of Plastics. Hanser Publishers.

Chen, L.P., Yee, A.F., Moskala, E.J., 1999. The molecular basis for the relationship between the secondary relaxation and mechanical properties of a series of polyester copolymer glasses. Macromolecules 32, 5944-5955. https://doi.org/ 10.1021/ma981363a.

Detrez, F., Roland, S., 2008. Nano-Scale Deformation Mechanisms in Semi-Crystallin Polymers: In Situ Atomic Force Microscopy Study and Modeling. Université Lille I.

Drozdov, A.D., Christiansen, J. deC., 2003. Nonlinear time-dependent response of isotactic polypropylene. J. Rheol. (N. Y. N. Y). 47, 595-618. 10.1122/1.1567753

Eiras, D., Pessan, L.A., 2009. Mechanical properties of polypropylene/calcium carbonate nanocomposites. Mater. Res. 12, 517-522. https://doi.org/10.1590/ S1516-14392009000400023.
Guerrica-Echevarría, G., Eguiazábal, J.I., Nazábal, J., 1996. Effects of reprocessing conditions on the properties of unfilled and talc-filled polypropylene. Polym. Degrad. Stab. 53, 1-8. https://doi.org/10.1016/0141-3910(96)00018-3.

Hinsken, H., Moss, S., Pauquet, J.-R., Zweifel, H., 1991. Degradation of polyolefins during melt processing. Polym. Degrad. Stab. 34, 279-293. https://doi.org/ 10.1016/0141-3910(91)90123-9.

Ingram, J., Zhou, Y., Jeelani, S., Lacy, T., Horstemeyer, M.F., 2008. Effect of strain rate on tensile behavior of polypropylene and carbon nanofiber filled polypropylene. Mater. Sci. Eng. A 489, 99-106. https://doi.org/10.1016/j.msea.2008.01.010.

Kolarik, J., 1996. Simultaneous prediction of the modulus and yield strength of binary polymer blends. Polym. Eng. Sci. 36, 2518-2524. https://doi.org/ 10.1002/pen.10650.

Matadi, R., Hablot, E., Wang, K., Bahlouli, N., Ahzi, S., Avérous, L., 2011. High strain rate behaviour of renewable biocomposites based on dimer fatty acid polyamides and cellulose fibres. Compos. Sci. Technol. 71, 674-682. https:// doi.org/10.1016/j.compscitech.2011.01.010.

Pessey, D., Bahlouli, N., Pattofatto, S., Ahzi, S., 2008. Polymer composites for the automotive industry: characterisation of the recycling effect on the strain rate sensitivity. Int. J. Crashworthiness 13, 411-424. https://doi.org/10.1080/ 13588260802030745

Pessey, D., Bahlouli, N., Raveyre, C., Guillet, J., Ahzi, S., Hiver, J.-M., Dahoun, A., 2010. Characterization of contamination effects for two polypropylene-based materials. Polym. Eng. Sci. 50, 1-9. https://doi.org/10.1002/pen.21451.

Rogueda-Berriet, C., Bahlouli, N., Pessey, D., Rémond, Y., 2011. Mechanical behavior of recycled polypropylene composites under tensile, bending, and creep loading: experimental and modeling. J. Eng. Mater. Technol. 133, 30907. https://doi.org/10.1115/1.4004051.

Rust, N., Ferg, E.E., Masalova, I., 2006. A degradation study of isotactic virgin and recycled polypropylene used in lead acid battery casings. Polym. Test. 25, 130 139. https://doi.org/10.1016/j.polymertesting.2005.08.009.

Serranti, S., Luciani, V., Bonifazi, G., Hu, B., Rem, P.C., 2015. An innovative recycling process to obtain pure polyethylene and polypropylene from household waste Waste Manag. 35, 12-20. https://doi.org/10.1016/j.wasman.2014.10.017.

Strapasson, R., Amico, S.C., Pereira, M.F.R., Sydenstricker, T.H.D., 2005. Tensile and impact behavior of polypropylene/low density polyethylene blends. Polym. Test. 24, 468-473. https://doi.org/10.1016/j.polymertesting.2005.01.001.

Tang, P., Brouwers, H.J.H., 2017. Integral recycling of municipal solid waste incineration (MSWI) bottom ash fines $(0-2 \mathrm{~mm})$ and industrial powder wastes by cold-bonding pelletization. Waste Manag. 62, 125-138. https://doi org/10.1016/j.wasman.2017.02.028.

Teh, J.W., Rudin, A., Keung, J.C., 1994. A review of polyethylene-polypropylene blends and their compatibilization. Adv. Polym. Technol. 13, 1-23. https://doi. org/10.1002/adv.1994.060130101.

Wang, C.-Q., Wang, H., Liu, Y.-N., 2015. Separation of polyethylene terephthalate from municipal waste plastics by froth flotation for recycling industry. Waste Manag. 35, 42-47. https://doi.org/10.1016/j.wasman.2014.09.025.

Zuiderduin, W.C.J., Westzaan, C., Huétink, J., Gaymans, R.J., 2003. Toughening of polypropylene with calcium carbonate particles. Polymer (Guildf). 44, 261-275. https://doi.org/10.1016/S0032-3861(02)00769-3. 